\title{
ELABORACIÓN DE UN PLAN* PARA LA CUALIFICACIÓN DE ASENTAMIENTOS EN MUNICIPIOS CONSOLIDADOS POR EL TURISMO
}

\author{
J. Fernando Vera Rebollo \\ Carlos Javier Baños Castiñeira \\ Arturo Jiménez Rodríguez
}

\section{RESUMEN}

Se presenta, en síntesis, el desarrollo de un proyecto de investigación conducente a la cualificación del modelo de implantación turístico-residencial, desde los presupuestos de desarrollo equilibrado y sostenido de esta actividad en un espacio costero consolidado y especializado. El objetivo es acometer una reestructuración global de la oferta y su adecuación a nuevas tendencias y motivaciones de la demanda. Propuestas tales como la limitación al crecimiento de nuevas plazas, la gestión frente a la producción de suelo, la dinamización de las plazas existentes y la superación de la perspectiva municipal en el desarrollo de nuevas ofertas son algunas de las claves que permiten diseñar el futuro de los destinos turísticos en este espacio litoral.

Palabras clave: turismo residencial, cualificación, reestructuración, actuaciones públicas.

* La realización del Plan para la Revitalización de Municipios con Turismo Residencial en la Costa Blanca, en el marco del Plan FUTURES (Secretaría General de Turismo), fue encomendada al Instituto Universitario de Geografía, constituyéndose para ello un grupo de trabajo que contó además con el concurso de profesionales como D. José Miguel Iribas Sánchez, sociólogo-urbanista. La cartografía del proyecto, dividida en dos clases (cartografía analítica municipal y temática), se realizó mediante el uso del software ARCAD, combinando herramientas SIG y CAD, tarea que corrió a cargo de J.M. Mira Martínez, geógrafo. 
The authors present, the development of a research project aimed at qualifying the existing tourist resort model in a consolidated and specialized coastal area, taking into account the balanced and sustained pretexts of tourism development. The aim is to achieve a global restructurisation both of supply, and of its suitability to new trends and motivations apparent in demand. Proposals such as limiting the growth of new beds, proper management as opposed to indiscriminate land use, giving a dynamic thrust to existing supply, and getting over the municipal perspective given to the development of new offers are some of the key questions which must be answered in order to properly design the future of coastal tourist resorts in this area.

Key words: residential tourism, qualitification, restructurisation, public policies.

\section{Características estructurales de la oferta turístico-residencial}

El modelo turístico del litoral alicantino, condigno a otras tantas áreas del arco mediterráneo, integra tipologías diferenciadas de desarrollo e implantación de la oferta; aunque todas ellas se asientan en el aprovechamiento de las ventajas comparativas inherentes al medio físico-ecológico y a las condiciones estructurales que han favorecido, desde los años sesenta, la configuración de entidades urbanoturísticas excesivamente masificadas y concentradas a lo largo del eje costero ${ }^{1}$.

Se percibe así, en el caso de la Costa Blanca, el enorme contraste existente, tanto en el plano morfológico, como en su repercusión económica y medioambiental, entre los asentamientos densificados del área funcional de Torrevieja, en el extremo meridional, frente a la implantación de más calidad en el tramo que se extiende desde el Cabo de La Nao hasta Moraira. Del mismo modo que, dentro de una misma unidad territorial turística, resulta notable la diferencia entre las urbanizaciones relacionadas y apoyadas sobre una oferta complementaria de calidad, como el caso del golf en el litoral de Orihuela, con relación a los conjuntos de apartamentos existentes en su misma zona costera, caracterizados por la masividad estacional de su ocupación y su enorme impacto ambiental.

Estos contrastes percibidos en cuanto a tipologías de asentamientos reflejan distintas condiciones estructurales de la demanda, verdadera clave explicativa de la configuración de las áreas turísticas, al tiempo que identifica mecanismos parti-

1 Para una caracterización del modelo turístico del litoral mediterráneo español Vera Rebollo, J.F. (1992): El modelo turístico, características y cambios, en Velarde, J. y otros (dir) Nuevos ejes territoriales de desarrollo: España en la Europa de los noventa. Colegio de Economistas de Madrid, Economistas Libros. Madrid, pp. 
culares en cuanto a promoción, gestión y explotación de la oferta, que tienen su reflejo más claro e interesante en la propia rentabilidad de las actuaciones y en las expectativas de futuro, cuando se trata de apostar por el ocio turístico como actividad sostenible. Por tanto, la intrinseca conexión entre tipos de demanda y modelos de oferta obliga a identificar las actuaciones inmobiliario-turísticas como verdaderos productos, puesto que son los asentamientos o urbanizaciones las verdaderas unidades de planificación y producción turística-residencial.

El denominado genéricamente como turismo residencial —en toda la amplitud y complejidad de su definición - se ha venido asimilando en este ámbito a la promoción inmobiliaria y venta de viviendas, tanto en conjuntos residenciales, (urbanizaciones particulares) como en ensanches de núcleos urbanos tradicionales para acoger a una demanda en continuo crecimiento durante las últimas décadas. Conviene recordar en este sentido que la oferta extrahotelera constituye la parte más sustancial del conjunto de plazas ofertadas, hasta el extremo que en la provincia de Alicante el total de plazas en hoteles y hostales suman 50.152, mientras que las existentes en apartamentos y viviendas relacionadas con el ocio multiplican esta cifra por más de diez. En su conjunto, la oferta hotelera del litoral es dispar, como ocurre en el resto de la Comunidad Valenciana, con una alta concentración en Benidorm (31.649 plazas en hoteles y 589 en hostales) y un nivel muy disperso y cuantitativamente menos significativo en otros tramos costeros. Así pues, la tipología de oferta de plazas dominante concede a la modalidad hotelera una importancia menor de la que tiene en áreas turísticas próximas como Cataluña y Baleares; la explicación a este hecho hay que buscarla en relación con el momento de implantación de la oferta y el sistema de actuación de los agentes empresariales.

En estas coordenadas, se ha entendido el desarrollo turístico como proceso de afectación creciente del uso del suelo hacia fines residenciales no permanentes - lo que diferencia este fenómeno de la ciudad convencional y de la forma de hacer ciudad-, pero se diferencia de la segunda residencia, propia del entorno de áreas urbanas y metropolitanas, por la comercialización de la oferta (importancia de los alquileres y, más recientemente, de la multipropiedad), la inserción de elementos complementarios al alojamiento (golf, náuticos, restauración, ocio y diversión) y la configuración de comunidades de residentes, con diferencias en los períodos de ocupación de los inmuebles que suelen responder al segmento específico de demanda de que se trata: tercera edad de origen nacional o europeo, vacacionistas, entre otros ${ }^{2}$.

2 Una distinción operativa para la planificación turística en nuestro ámbito lleva a diferenciar entre turista, vacacionista y residente, sobre la base de criterios como son la tasa de estancia, organización del viaje, medio de transporte empleado, tipo de alojamiento, composición del grupo, tendencia al gasto, comportamiento y efectos sobre la estructura urbana y socioeconómica. Ver cuadro 1. 
Los municipios litorales de la Costa Blanca ofrecen un buen muestrario de estas tipologías, consecuencia de una larga trayectoria, de la que deriva la exigencia misma de acometer reformas, a fin de combatir los aspectos que dificultan hoy la competitividad de tales modelos y la necesidad de revitalizar estas entidades, a veces verdaderos modelos pseudourbanos que precisan nuevos elementos dinamizadores, en consonancia con los propios cambios experimentados desde el lado de la demanda y las mismas exigencias de calidad ambiental y desarrollo sostenible para las áreas donde se asientan, tras una etapa centrada en el crecimiento continuado de la oferta y la producción de suelo como mecanismo de actuación.

El problema esencial se centra en una política de producto, que deberá acompañarse de la puesta en funcionamiento de otras vías de competitividad escasamente aprovechadas (marketing, comercialización, distribución del producto). Para ello se plantea la necesidad de especializar ofertas, acordes con las motivaciones de los consumidores y de diversificar productos, en consonancia con los mecanismos de producción-construcción del suelo residencial-turístico que han sido los dominantes en el modelo objeto de estudio. Un modelo que tiene y debe seguir teniendo como referencia esencial el aprovechamiento del sol y el mar, aunque afianzando ahora verdaderas ventajas competitivas, mediante actuaciones con mayor valor añadido que no resulten esquilmantes con los recursos y activos naturales y culturales en que se sustentan.

Por tanto la cualificación de las actuaciones y diversificación de sus elementos, en paralelo a la recomposición estructural de las áreas consolidadas, se presentan como claves de actuación en el Programa de Revitalización desarrollado, entendido como verdadero plan de choque frente al deterioro y pérdida de competitividad señalados. Todo ello a pesar de la favorable coyuntura de la temporada 1994, cuyas cifras de ocupación —además de que se basan exclusivamente en la ocupación hotelera- podrían llamar a engaño con relativa facilidad, puesto que no se han modificado sustancialmente las variables que afectan negativamente a la demanda, salvo los precios; lo que demuestra la precariedad de la situación, al tiempo que persisten problemas estructurales: deterioro de la calidad en relación con los precios, insuficiencia de las infraestructuras y equipamientos, degradación ambiental, rigideces de la oferta e inadecuación a la demanda, falta de profesionalidad, escasa sensibilidad social sobre la importancia misma del turismo, entre otros aspectos negativos que deben ser mejorados.

Desde diferentes trabajos que reflejan la evolución del modelo turístico del litoral se ha venido apuntando que, tras la fase de construcción masiva del sistema y una vez configurados los desarrollos, se trata ahora de buscar vías para afianzar la rentabilidad, a través de alternativas sostenibles que reposicionen el producto, mediante la corrección de las deficiencias detectadas y la 
definición de estrategias que respondan a los ya señalados cambios que se detectan en la demanda ${ }^{3}$.

Se trata por tanto de un problema de relación entre producto y mercado, que obliga a establecer medidas e instrumentos para la reestructuración y revitalización de los destinos turísticos y la planificación estratégica de formas de desarrollo sostenibles; en consecuencia, un problema de ciclo de vida del producto. Algo similar a lo que se planteó hace ya bastantes años en áreas turísticas que se vieron sometidas a procesos de declive y en las que se proyectan actuaciones encaminadas al reposicionamiento del producto (podría ser el caso del Suroeste del Reino Unido).

La necesaria reconceptualización de las actuaciones turísticas, tras la construcción indiferenciada de paquetes de alojamiento, en forma de conjuntos residenciales o bloques de apartamentos, impulsa a establecer nuevos mecanismos de promoción, gestión y explotación del producto. Con ello se intenta hacer frente a la situación de deterioro mediante la transformación del producto convencional, al tiempo que se identifican nuevos activos y oportunidades empresariales.

En el caso de los destinos turísticos de la Costa Blanca, este tipo de actuaciones supone dar cumplimiento a la voluntad manifestada desde la política turística, cuando se hace referencia a la competitividad del modelo turístico: Libro Blanco del Turismo de la Comunidad Valenciana, elaborado por el Institut Turistic Valencià y Plan Marco de Competitividad del Turismo Español, de la Secretaría General de Turismo.

En suma, el trabajo que se presenta responde a una preocupación social e institucional, cuando se trata de encontrar soluciones que dinamicen estos espacios volcados a la vertiente residencial del turismo. La definición de un marco de reestructuración global debe ser entendida como un impulso desde las administraciones, en este caso la Diputación Provincial, para sentar principios de actuación y establecer un modelo de referencia capaz de encauzar, ilusionar y motivar las iniciativas privadas.

\section{Objetivos propuestos y mecanismos de coordinación}

El Plan parte del propósito de articulación de una política turística eficaz para la reactivación de los municipios consolidados por los asentamientos turístico-residenciales, para lo que se señalan objetivos genéricos tales como la limitación al crecimiento de nuevas plazas en el litoral, la apuesta por la gestión turística frente a la producción de espacio, la necesidad de dinamizar

3 VERA, J.F. y MONFORT, V.M. (1994): Agotamiento de modelos turísticos clásicos: una estrategia para la cualificación. La experiencia de la Comunidad Valenciana, en Estudios Turísticos, $\mathrm{n}^{\mathrm{o}} 123$, Instituto de Estudios Turísticos, Madrid. 
las plazas turísticas existentes, junto con la mejora de la estacionalidad. Del mismo modo se intenta propiciar la singularidad de la oferta y los principios de complementariedad intermunicipal. En suma, la reordenación de los espacios litorales en cuanto a su estructura de oferta. Desde estos principios se concretan objetivos específicos sobre el producto:

* Afianzar el liderazgo en el producto residencial sustentado en la valoración de las condiciones ecológicas y activos turísticos, así como en ventajas comparativas derivadas de la calidad de los servicios y la diversificación del producto masivo.

* Afirmar el papel del turismo como factor de reequilibrio territorial y socioeconómico, al hacer intervenir en el futuro desarrollo a otros ámbitos espaciales que trascienden de límites de la franja costera actualmente urbanizada. Utilizar la oferta complementaria y los nuevos productos como posibilidades de reorganización territorial.

* Establecer líneas encaminadas al saneamiento del producto turístico, mediante la recuperación de áreas degradadas, introducción de innovaciones y mejora ambiental y estética, con particular atención a la calidad y eficiencia de las infraestructuras y equipamientos.

* Sentar principios y bases de actuación para una política de producto desde la escala local y comarcal, identificando nuevas oportunidades y expectativas empresariales. Se trata de evitar conflictos entre municipios vecinos y hacer hincapié en la articulación de ámbitos y productos diferenciados.

* Definir posibilidades para dinamizar los destinos turísticos mediante una oferta comercial apoyada en el sustrato urbano existente y en la creación de áreas de nueva centralidad.

* Marcar prioridades en la asignación de recursos naturales en aras del desarrolo turístico sostenible y respetuoso con el medio ambiente.

* Identificar y definir mecanismos de gestión/explotación para el producto turístico inmobiliario que no se limite a la promoción de suelo y construcción masiva e indiferenciada de alojamiento.

* Valoración del patrimonio histórico cultural como activo turístico, desaprovechado e infrautilizado, proponiendo la recuperación de entornos, conjuntos, singularidades, elementos tipológico-tradicionales, en el conjunto de una ordenación integral del producto.

* Delimitar áreas problema, en relación con carencias detectadas, y sentar pautas para su corrección, con la finalidad de mejorar la calidad de vida en los municipios turísticos.

* Hacer partícipes del proyecto a los agentes públicos y privados que deben impulsar las mejoras: ayuntamientos, empresarios, sindicatos, entre otros.

Se pretende elaborar un documento capaz de integrar propuestas globales, expresivas de una política a largo plazo, desarrolladas en actuaciones más de 
detalle, a impulsar desde distintos niveles de la administración, facilitando pautas y referencias para la concertación con los agentes privados.

Para ello resulta además esencial garantizar la coordinación técnica con otros planes que se elaboran desde la Generalitat Valenciana y, de forma especial, el Plan Director de los Espacios Turísticos (PLADET), documento de planificación de carácter estratégico, que pretende ser un marco de referencia global para orientar las actuaciones de los diferentes agentes públicos y privados involucrados, reafirmando su carácter supramunicipal.

Las actuaciones además de integrarse en las prioridades de la Diputación Provincial, podrán recogerse en el citado PLADET o en los programas de actuación del ITVA, mientras que otras acciones de carácter estrictamente sectorial atañen a distintos niveles y departamentos de la administración, como consecuencia del mismo carácter multiforme del turismo.

Especial importancia tienen, al hablar del turismo residencial, las actuaciones referidas al urbanismo. En tal sentido, se pretende que las propuestas sirvan a la hora de revisar y redactar los documentos de planeamiento urbanístico municipal, como soporte de políticas turísticas orientadas a la cualificación del producto y protección medioambiental. En suma, en la voluntad de coordinación administrativa y la vinculación efectiva del Plan residen las posibilidades de éxito de esta iniciativa.

\section{Problemas a resolver}

Los deterioros detectados son la consecuencia del desarrollo casi espontáneo, improvisado en bastantes ocasiones, donde los mecanismos de transformación del uso del suelo, conducidos por los impulsos de la demanda, exceden las posibilidades de control y capacidad de gestión de las Administraciones Locales. La escasa capacidad de respuesta de los ayuntamientos, el deslumbramiento de corte economista ante las inversiones realizadas en el último período (sin que falte un claro componente especulativo) y la propia masividad del fenómeno, justifican los niveles de deterioro a los que se ha llegado, especialmente en aquellos municipios que tradicionalmente no se han volcado a la prestación de servicios turísticos y en los que el proceso se desencadena de forma rápida en el último decenio. Este es el caso de pequeñas entidades del sur de la provincia, donde los rasgos de masividad e improvisación generan notables disfunciones y un mayor volumen de desaprobación por parte de la demanda.

En una primera aproximación, los problemas detectados y, por consiguiente, la definición de ámbitos y parcelas de actuación queda reflejada, de acuerdo con los resultados de la encuesta realizada entre los residentes en asentamientos, junto con los datos de las informaciones básicas, referidas a aspectos urbanísticos, territoriales y ambientales, recabados por el equipo de trabajo. 
Los cuadros que se adjuntan sintetizan los resultados de la encuesta realizada a residentes dentro del área de trabajo y ponen de manifiesto la percepción sobre distintos aspectos relativos a equipamientos, infraestructuras municipales y servicios públicos, así como el estado de cada asentamiento turístico-residencial. No menos importante resulta la valoración de aspectos cualitativos referidos al medio ambiente y paisaje, así como la síntesis del municipio entendido como producto global, valorado en términos de calidad de vida.

\subsection{Infraestructuras, equipamientos y servicios}

En el apartado de infraestructuras básicas y a escala de los grandes conjuntos supramunicipales delimitados, destaca como tema esencial el abastecimiento del agua potable, de forma que se acusa el contraste manifiesto entre las áreas afectadas por sistemas de abastecimiento público, que se constituyen en verdadera garantía para el suministro en cantidad y calidad, tal es el caso del sur, abastecido por la Mancomunidad de Canales del Taibilla, donde sólo los conjuntos residenciales que no están conectados a las redes municipales padecen algún tipo de problema. Del mismo modo que en la Marina Baja se percibe el efecto positivo del Consorcio.

Los problemas relativos al alcantarillado y depuración presentan niveles distintos entre el litoral norte y el sur; así las redes de alcantarillado en conjuntos residenciales escasean desde el litoral ilicitano hasta Denia (no aparece este tipo de infraestructura entre un 30 y un $60 \%$ de las urbanizaciones); mientras que en los municipios del sur, la carencia es sensiblemente menor (sólo un $30 \%$ o menos de las urbanizaciones no tienen alcantarillado). Por su parte, la falta de depuración es más notable entre Altea y de Denia que hacia al centro y sur de la Costa Blanca.

Las mayores deficiencias de infraestructura en los municipios del norte se vuelven a presentar cuando se observa que el alumbrado público escasea más entre la Vila Joiosa y Denia (entre un 30 y $60 \%$ de las urbanizaciones carecen de servicio), mientras que la situación es considerablemente mejor en los municipios del sur provincial. Algo similar se repite con las aceras de las urbanizaciones, inusuales en los modelos difusos del norte.

Es especialmente incomoda la falta de señalizaciones de todo tipo observada en gran parte de las urbanizaciones, especialmente en las de grandes dimensiones, tanto en cuanto a direcciones dentro de ellas como en la localización exacta en cada momento. Da la impresión de que los residentes, que conocen perfectamente la zona, prefieran esa intimidad derivada de la falta de información, a pesar de los problemas que soportan los visitantes o en ocasión de evacuaciones urgentes.

Otro de los principales problemas detectados y del que participan casi todos los espacios estudiados es el que tiene que ver con la red viaria, tanto la interior de cada urbanización como la red general que evacúa el tráfico generado por aquéllas. 
Al gestarse cada una de las distintas actuaciones urbanísticas de espaldas al resto de promociones, se ha generado una estructura viaria desorganizada y sin trabazón, que al pivotar de manera general sobre una única $\mathrm{CN}$, generalmente la 332, los atascos y congestión resultan acontecimientos «normales» en determinadas épocas del año.

\section{CUADRO 1}

\begin{tabular}{|c|c|c|c|}
\hline \multicolumn{4}{|c|}{ CARACTERIZACIÓN DE LA DEMANDA EN LA COSTA BLANCA } \\
\hline CONCEPTO & TURISTAS & VACACIOHISTAS & RESIDENTES \\
\hline TASA DE ESTANHCIA & 15 dlas o menos & 20 a 60 diag & 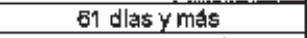 \\
\hline $\begin{array}{l}\text { ORGANIZACIÓN DEL } \\
\text { WIAJE Y LA E\$TANGIA }\end{array}$ & $\begin{array}{l}\text { Preferentemerute a trawes de } \\
\text { megranismos de mediaciòn }\end{array}$ & Por ewenta propia & Por cuenta propia \\
\hline $\begin{array}{l}\text { MEDNO DE LOCOMOCIÓN } \\
\text { EMPLEADD }\end{array}$ & $\begin{array}{l}\text { Transperte colectivo mo } \\
\text { regular }\end{array}$ & Tramsporte individual & Transportee indrididual \\
\hline TIPO DE ALOJAMIENTO & $\begin{array}{l}\text { En hoteles, campings o } \\
\text { yiriendas en alquiller, } \\
\text { generalmente apartarnentos }\end{array}$ & 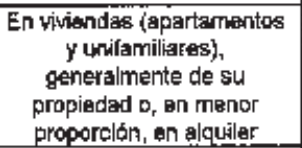 & $\begin{array}{l}\text { EF wiviendas de su } \\
\text { propiedad, generalmente } \\
\text { unifamiliares }\end{array}$ \\
\hline $\begin{array}{l}\text { COHPOSICION DEL } \\
\text { GRUPO }\end{array}$ & Menog de 3,5 personas & Superior a 3,5 pertonat & $\begin{array}{c}\text { Inferior a } 2 \text { personag courno } \\
\text { promedio }\end{array}$ \\
\hline $\begin{array}{l}\text { TENDENCIA ÁL OASTO } \\
\text { (extras y diwarsiones) }\end{array}$ & $\begin{array}{c}\text { Alta (3.500 pesetas a mfs } \\
\text { por persond y y d la) }\end{array}$ & $\begin{array}{l}\text { Moderada (da } 2.000 \text { a } 2.500) \\
\text { pestevas por persona y dfa) }\end{array}$ & $\begin{array}{l}\text { Baja }\{1,000 \text { pesetas por } \\
\text { perpone y dla o menos }\}\end{array}$ \\
\hline COHPORTAMLENTO-TIPO & 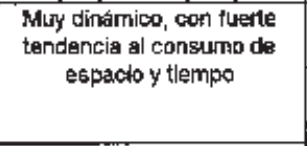 & $\begin{array}{l}\text { Estauco, con lendencia a un } \\
\text { comsumo selectho de } \\
\text { espacio (hacia lugares no } \\
\text { generadores de gasto') }\end{array}$ & 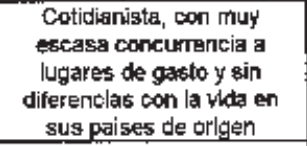 \\
\hline \multirow[t]{5}{*}{$\begin{array}{l}\text { EFECTOS SOBRE LA } \\
\text { ESTRLCTURA URBANA Y } \\
\text { ECONOHICA }\end{array}$} & $\begin{array}{l}\text { Modelos urbenoz de atta } \\
\text { eoncentracion y densidad }\end{array}$ & $\begin{array}{c}\text { Tramas rurales denisificadas } \\
\text { y, en menor medida, } \\
\text { ubanizaciones. }\end{array}$ & $\begin{array}{c}\text { Tramas nurales dengificades } \\
\text { Y. preferentementer } \\
\text { urbanizacjones }\end{array}$ \\
\hline & $\begin{array}{l}\text { Alto nivel de serledidad y } \\
\text { complejidad de servicios. } \\
\text { Alto grada de autonomita } \\
\text { funciona: }\end{array}$ & $\begin{array}{l}\text { Coberturg suliciente de } \\
\text { servicios besicicos. Bajo niwal } \\
\text { de servicios singulares. } \\
\text { Moderado nlyel de } \\
\text { dependencig }\end{array}$ & 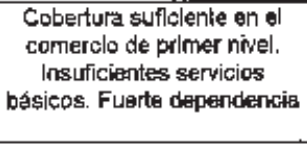 \\
\hline & 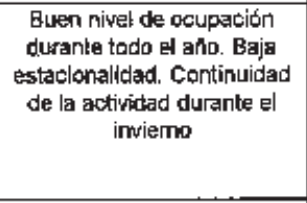 & $\begin{array}{l}\text { Escaso niugl de octpación } \\
\text { durante lós theses huera de } \\
\text { la temporada de verano. } \\
\text { Fuerte estacionalindad }\end{array}$ & 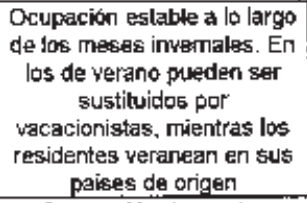 \\
\hline & 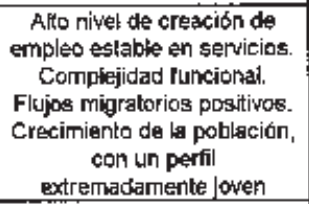 & 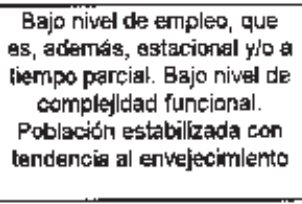 & 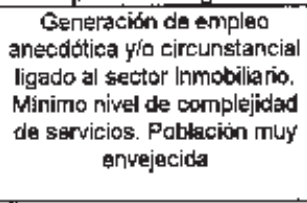 \\
\hline & 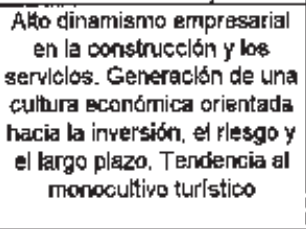 & 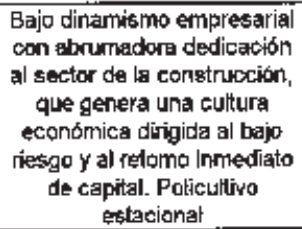 & 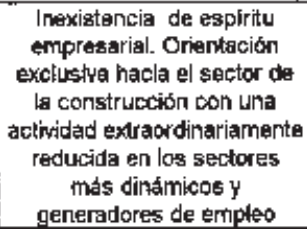 \\
\hline
\end{tabular}

Fuente: Bases para la redacción del Plan Director de los Espacios Turísticos de la Comunidad Valenciana. Fundación Cavanilles de Altos Estudios Turísticos. Alicante, 1995. 


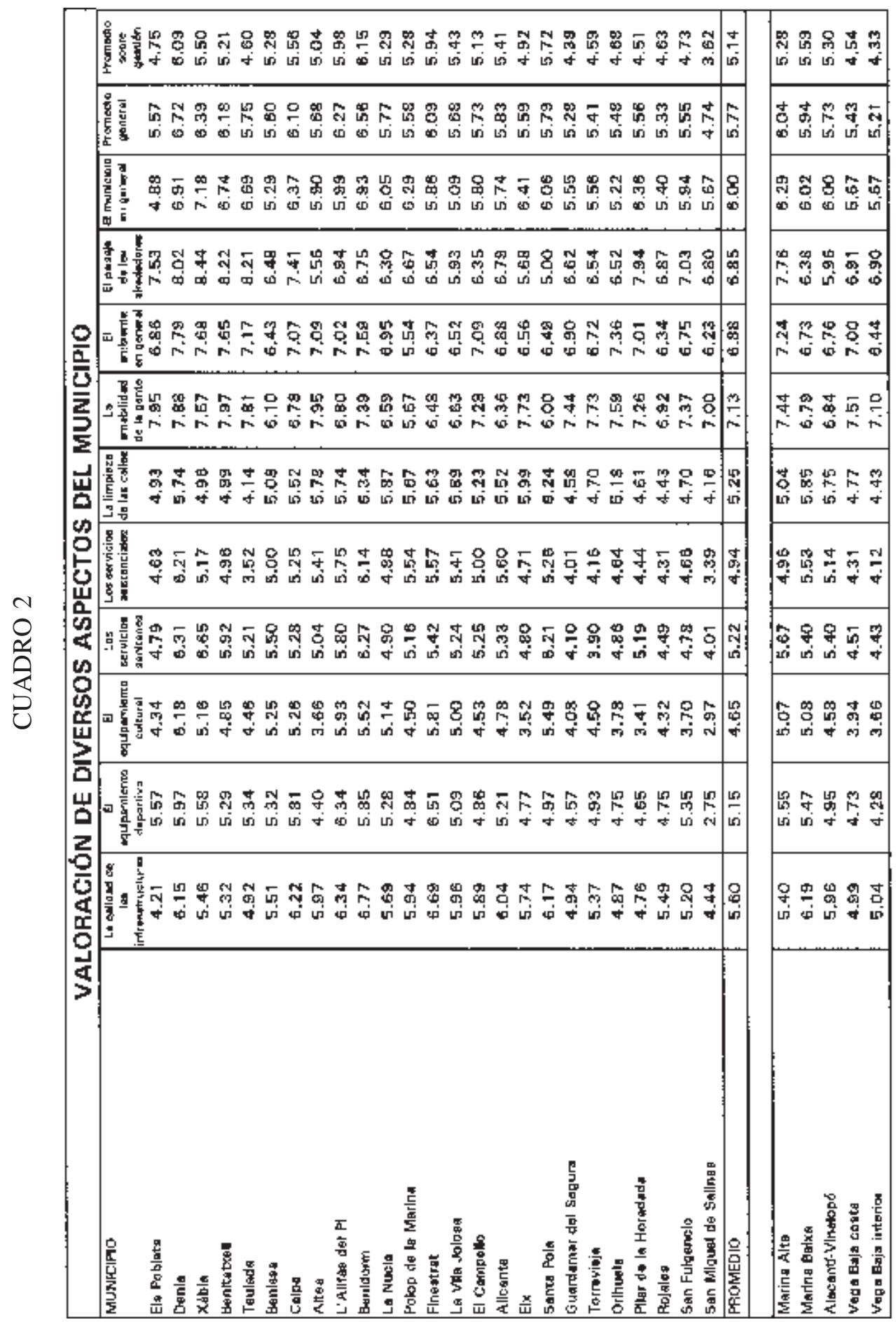




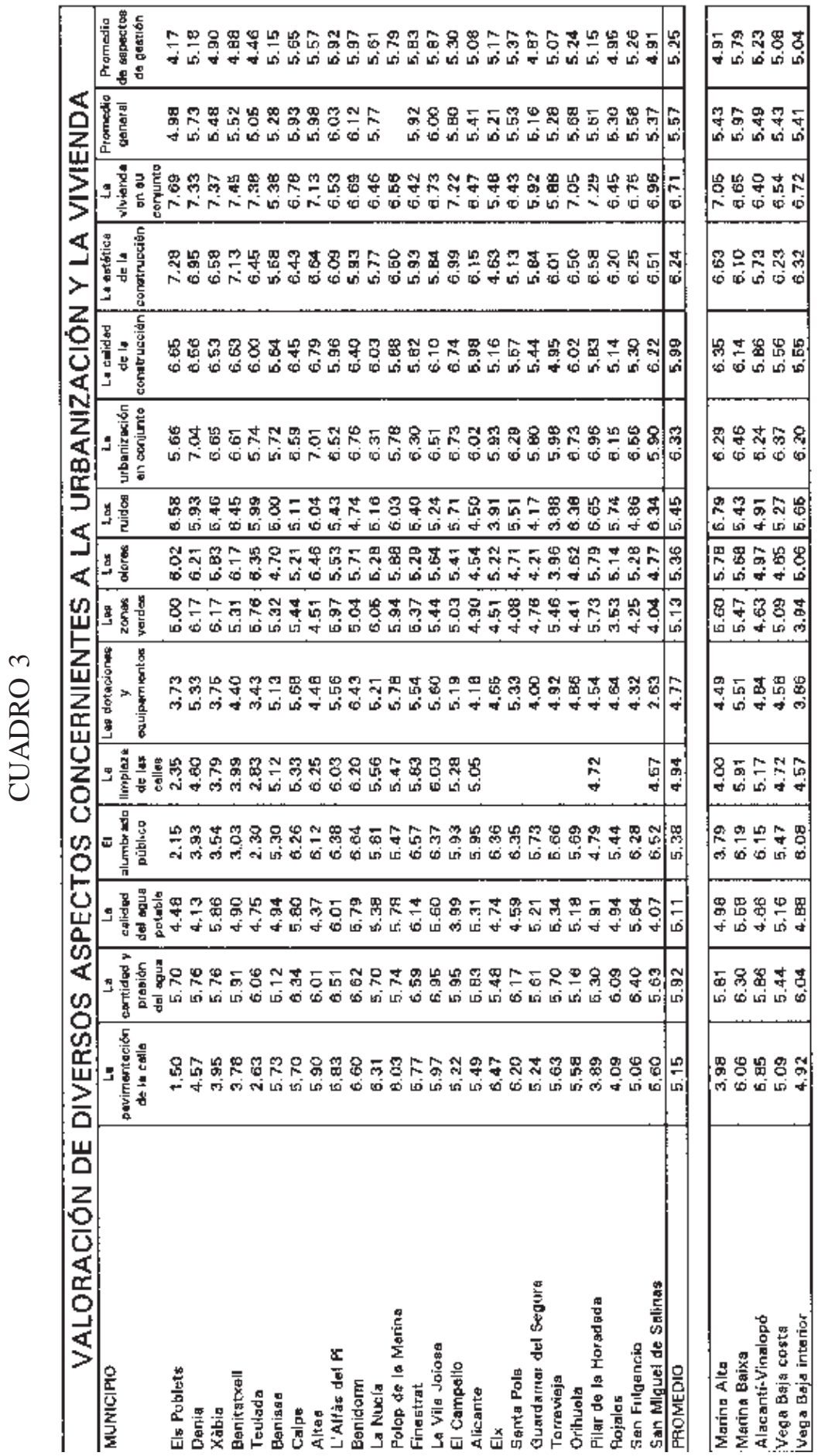


No menos interés tiene la situación de los servicios públicos, tema en el que sorprende la situación detectada en el modelo de localización de hospitales, si se pretende consolidar el asentamiento de población, ya que las áreas con mayor peso del residencialismo están a más de treinta minutos de un hospital comarcal: la costa de Orihuela y Torrevieja y el espacio comprendido entre Calpe y el sur de Moraira. En la misma línea, se detectan vacíos y dependencias fruto de inercias históricas, en temas como las comisarías de policía (concentradas en cabeceras comarcales tradicionales, con la única excepción de Benidorm) y los juzgados, donde vuelve a destacar el tema en el litoral sur, que depende de la capital oriolana, distante más de treinta minutos de la costa y con dificultades de acceso.

Las diferencias que se observan en cuanto a infraestructura y equipamientos, deterioro del entorno, servicios, etc., guardan una estrecha relación con las etapas y modelos de implantación de la oferta inmobiliaria en el espacio estudiado. Así, es manifiesta la falta de equipamientos residenciales en los conjuntos residenciales entre El Campello y Denia, consecuencia de su mayor antigüedad, ausencia de planeamiento urbanístico en las actuaciones y atomización de las iniciativas empresariales (parcelaciones rústicas en buena parte), independientemente de que coincide con las áreas de menor densidad (viv./ha.) y mayor calidad de los inmuebles. Cabe resaltar el ejemplo de Moraira, espacio de gran calidad paisajística, donde se localizan asentamientos con residentes de alto nivel adquisitivo, a pesar de que se detectan carencias evidentes en sistema de alcantarillado, depuración, alumbrado, servicios públicos, entre otros, en relación con el modelo turístico difuso y errático, propio de la comarca de La Marina. Por contra las actuaciones urbanísticas del sur, surgidas del planeamiento parcial, concentran, aun con deficiencias, mejores infraestructuras básicas, equipamientos y servicios públicos. Aunque se caracterizan por la masividad y altas densidades, vivienda de menor calidad y mayor impacto ambiental de los asentamientos.

La estacionalidad en la ocupación de determinados espacios con turismo residencial condiciona la ubicación, también en época estival, de determinados servicios y dotaciones, tales como estafeta de correos, farmacias, mercados, entre otros. Este hecho se ve agravado cuando se trata de urbanizaciones alejadas y desconectadas del núcleo urbano central, más que por la distancia que existe, por el tiempo que se tarda en acceder a aquél, debido a la congestión a la que se ve sometida en determinados periodos la red viaria que articula todos esos asentamientos.

\subsection{Agresiones al medio ambiente}

A la hora de sintetizar problemas, en relación con las actuaciones inmobiliarioturísticas, la degradación medioambiental se presenta como cuestión clave para la mejora de la competitividad del producto; así se reconoce en el Plan FUTURES, en cuyos programas estratégicos se incardina el presente trabajo. En este sentido el 


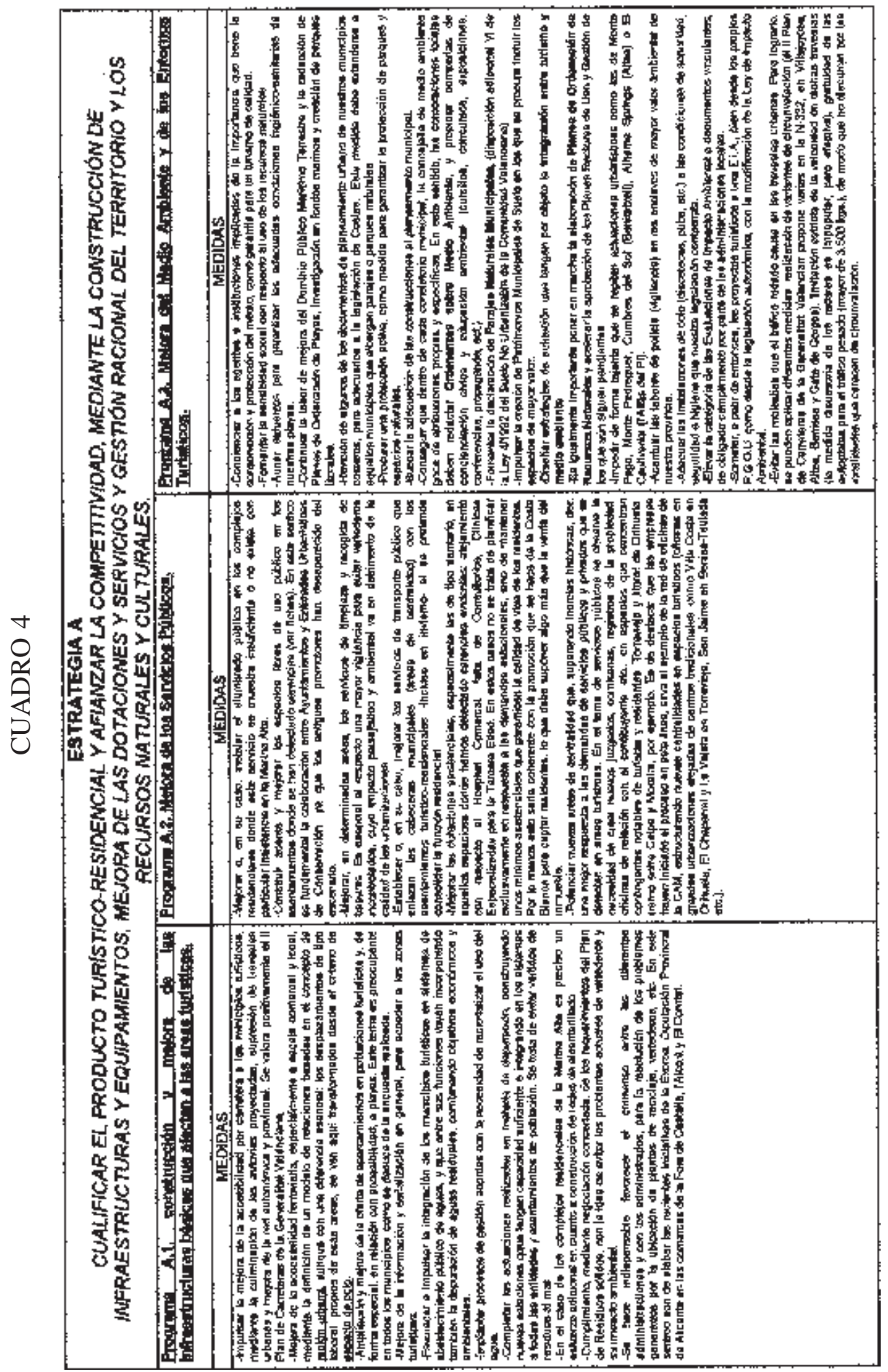




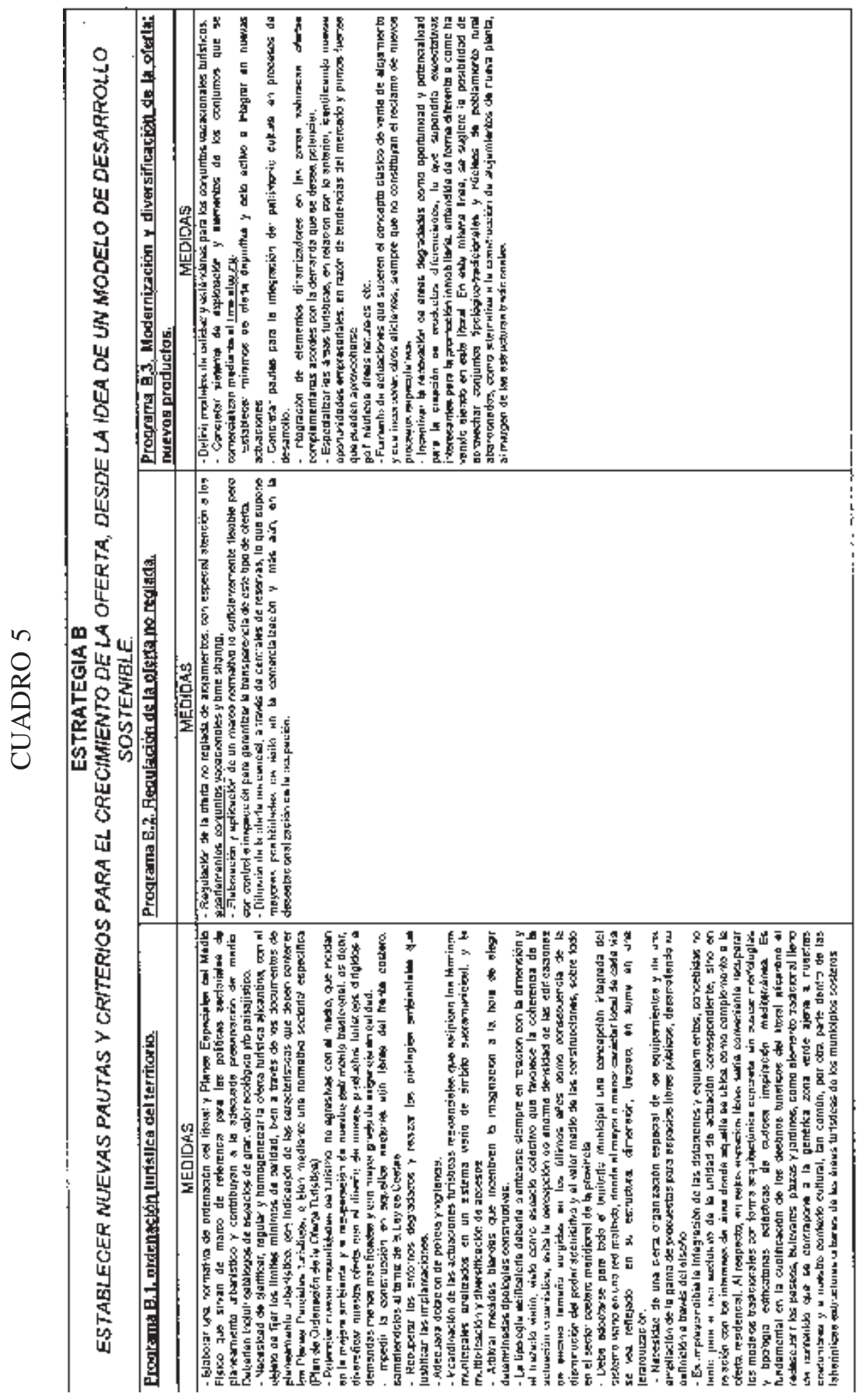




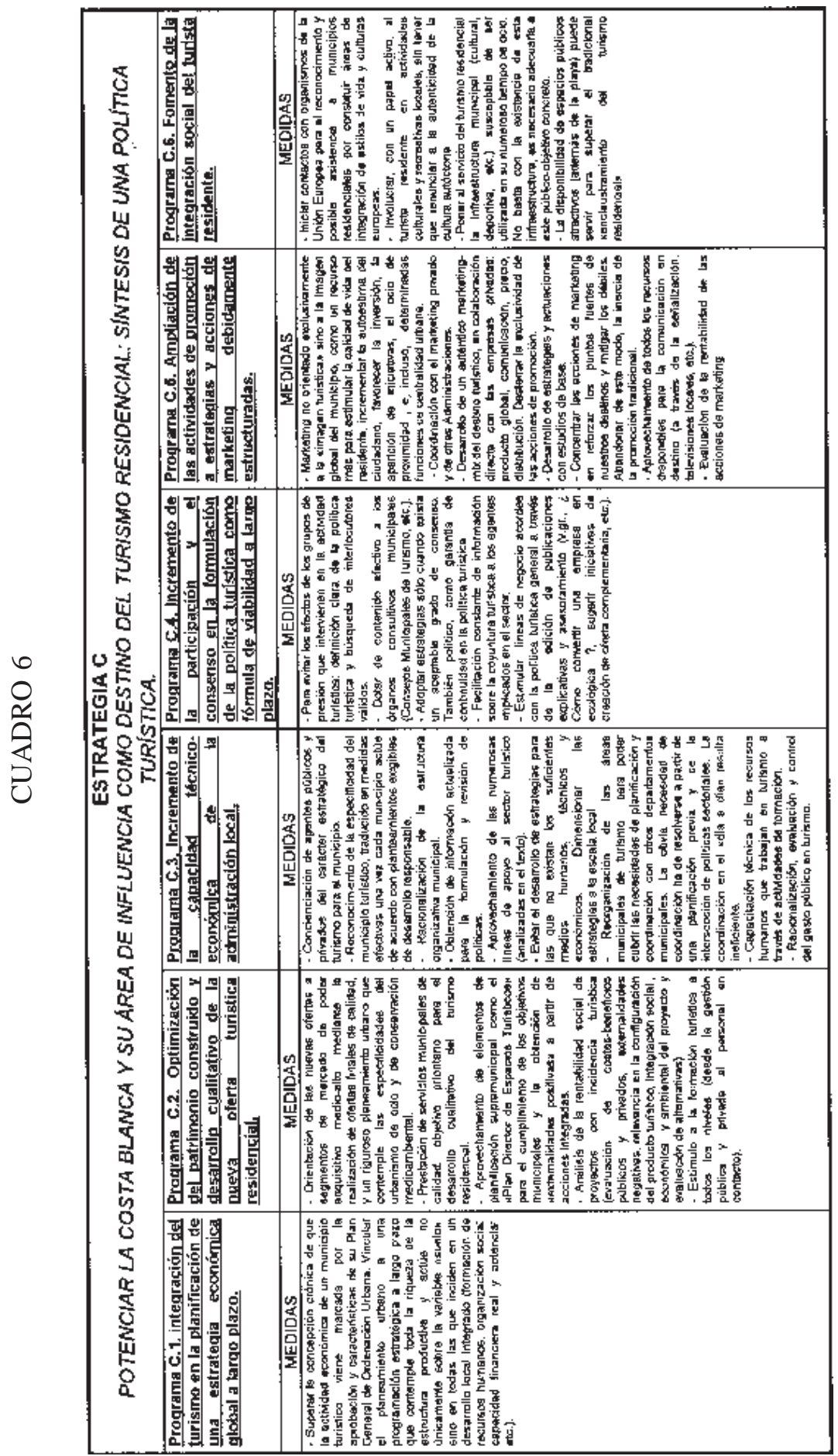


análisis pormenorizado de los principales impactos ambientales arroja resultados que, sin llegar a límites alarmantes de deterioro, obligan a acometer actuaciones de mejora, recuperación y conservación, así como a la necesidad de establecer mecanismos de gestión más acordes con el concepto de desarrollo sostenible de la actividad.

Los impactos más notables de la actividad se relacionan con la implantación de alojamientos e infraestructuras turísticas, entre los que destaca la ocupación del Dominio Público Marítimo-Terrestre (Guardamar, Elche, entre otros), la construcción de paseos marítimos sobre cordones dunares (San Juan, Urbanova, La Mata, Guardamar), la alteración de cauces y construcción en lechos de cauces y barrancos (a lo largo de toda la costa), la construcción masiva en torno a enclaves de valor ambiental (ladera del Montgó, Puig de la Llorençà, El Mascarat, Arenales del Sol, Cabo de Santa Pola, Lagunas de Torrevieja) y el deterioro de las perspectivas paisajísticas, cuestiones que deben ser objeto de atención desde la Conselleria de Medio Ambiente y los propios Ayuntamientos. Por su parte, otros impactos se relacionan con las deficiencias de infraestructuras, entre las que destaca el vertido de efluentes directos al mar (sucede en áreas concretas de Denia, Jávea, Benissa, Calpe, Altea, Benidorm, La Vila, El Campello, Alicante, Santa Pola, El Pilar de la Horadada) y la contaminación de las aguas del mar, detectada en la Bahía de Alicante y en la playa de El Pinet. No menos preocupante es el problema de los vertederos incontrolados y escombreras, que tanto dañan la imagen de los municipios turísticos, ya que, además, se suelen localizar a lo largo de las carreteras y vías de acceso a las urbanizaciones y núcleos. En cuanto a los vertederos «controlados», ocupan lugares cuyo valor ambiental y paisajístico se ve dañado, a veces de forma irreversible; en este aspecto el Plan de Residuos Sólidos contribuirá a solventar el problema, pero es aconsejable tomar medidas en casos como la Sierra de Oltá, el Cerro Cortina, la Sierra de Santa Pola, la Dehesa de Campoamor, por el enorme impacto que, a todos los niveles, generan las acumulaciones de residuos sólidos urbanos y el riesgo de incendios en las áreas afectadas, ya que suelen coincidir con espacios forestales y de monte bajo. En suma la problemática ambiental turística exige actuaciones coordinadas de las administraciones (local y autonómica) y una nueva cultura entre los habitantes, permanentes y estacionales, de estas áreas.

\subsection{Diversidad de la oferta residencial}

Las tipologías residenciales preferidas varían entre las viviendas unifamiliares aisladas y las viviendas unifamiliares adosadas en fila, siendo esta última la más solicitada en actuaciones recientes De igual modo la vivienda aislada es la más representativa en áreas forestales, donde las actuaciones urbano-turísticas se han ido consolidando por generación espontánea, al margen de cualquier mecanismo 
de ordenación territorial. Con todo, de manera especial en las urbanizaciones de compactación reciente, se tiende generalmente a la utilización de un diseño único, repetido hasta la saciedad, utilizando en cada caso un pretendido elemento de identificación de una determinada área geográfica, como son los riu-rau en la comarca de La Marina u ornatos arabiformes en zonas más meridionales. Además de recurrir a la solución de la vivienda unifamiliar adosada, en las actuaciones más recientes se ha increntado sensiblemente las densidades de viviendas/Ha, obviamente para conseguir mayores beneficios mediante construcciones seriadas y baratas. En este sentido cabría recordar que el manifiesto hacinamiento que esas elevadas densidades producen va en contra de la calidad de vida demandada por la población, que busca cada vez más la cualificación de la oferta mediante el incremento de la calidad antes que abaratando los precios de compra. La toma de conciencia de ese hecho puede ser lenta pero a largo plazo beneficiosa para el futuro de la actividad turística, especialmente en su vertiente de asentamiento de población semipermanente.

En definitiva, cuando se habla de asentamientos la correspondencia entre propuesta formal (proyecto) y realización práctica (realidad) suele ser escasa sobre todo en lo que hace referencia a espacios de uso público y dotacional, minusvalorados casi siempre y relegados a localizaciones marginales, sin atención alguna a diseño, mantenimiento y operatividad. Abundando en ello, la ausencia total de atención al entorno natural próximo, tanto en espacios interiores como en el tratamiento del borde marítimo, genera una merma considerable en la calidad ambiental y cualificación de la oferta, en clara contradicción con los deseos de aumento de competitividad de nuestro producto turístico.

Es significativo que la dotación de arbolado en zonas verdes comunes se haya visto reducida paulatinamente a lo largo del tiempo y, cuando existe, rara vez está en condiciones de dar servicio a la comunidad, al coincidir en su localización con ramblas y barrancos o áreas más inaccesibles para cumplir con los requerimientos de la legislación urbanística vigente. Obviamente, con ello la calidad ambiental de esos conjuntos urbanizados se reduce bastante, sobre todo en promociones del sur de la provincia, donde la vegetación natural es menos densa y por comparación esas carencias de zonas verdes públicas adecuadas son más perceptibles. Otro tanto ocurre con las áreas de deporte, tratadas como espacios marginales, que la mayor parte de las veces son parcelas y sin edificar.

En definitiva, el esquema de distribución de zonas verdes y áreas de deporte se superpone de ordinario a espacios de menor capacidad de aprovechamiento edificatorio y con peores condiciones clinométricas. Por ello creemos conveniente que se exija, previa a la aprobación municipal, el cumplimiento efectivo de los estándares previstos y su realización práctica, puesto que toda carencia que no se subsane en el período de dependencia del Plan Parcial respecto al promotor y se convertirá después en un problema añadido para los ayuntamientos. 
Estos procesos son particularmente notables en el área del sur, donde la función veraniega tradicional -inherente a la propia idiosincrasia de sus poblaciones (casos emblemáticos en Torrevieja y Santa Pola) - se ve transformada de forma casi radical en un período de diez años, en paralelo al declive irreversible de las actividades consideradas tradicionales (pesca, explotación salinera, agricultura de secano). La falta de preparación técnica de las administraciones locales, la ausencia de criterios a otra escala superior - salvo la voluntad de crecimiento continuado de la demanda y la oferta - la inadecuación de la legislación urbanística convencional para hacer frente a los mecanismos del urbanismo turístico y el apetito desmesurado de determinados agentes económicos, permiten entender los problemas indicados.

En el caso del litoral norte, el despegue turístico residencial, aun contando con estructuras veraniegas tradicionales, se produce con antelación (años sesenta) y de forma menos masiva que en los municipios del litoral meridional. Es así como destaca la ausencia de cualquier planeamiento y la parcelación de predios rústicos, como mecanismos de producción inmobiliario-turísticos, aunque la mayor solvencia de la demanda y el predominio de asentamientos de baja densidad justifican deterioros menos notables; si bien son aquí más claros los déficits en equipamientos e infraestructuras básicas.

El modelo más conflictivo, por sus dificultades actuales en cuanto a ordenación y gestión y ausencia de empresarios turísticos, corresponde a los municipios de marcada tradición rural, cuya cabecera principal de población no suele estar localizada junto a la ribera del mar (a veces ni siquiera el término municipal linda con el mar) y en los cuales la eclosión del proceso urbanizador supone el desmantelamiento de sus estructuras o la configuración de una realidad dual, desde el punto de vista económico-territorial, al crearse un espacio manifiesto de vivienda y alojamiento de ocio, segregado espacial y funcionalmente de la realidad tradicional del municipio, representada por su núcleo principal de población, que se muestra incapaz de convertirse en sustrato urbano de prestación de servicios (San Fulgencio, Rojales). Con ello se generan nuevas pseudocentralidades (La Escuera, Ciudad Quesada) y se redefinen relaciones funcionales de dependencia: es el caso del importante rango que alcanza Torrevieja en el litoral sur, como centro de un enorme espacio urbanizado por el ocio turístico.

Es perceptible por tanto el mayor grado de afianzamiento de las funciones turísticas y de ocio en municipios con tradición veraniega (Denia, Calpe, Benidorm, Santa Pola, Torrevieja), pero en algunos de éstos la eclosión del proceso urbanizador, en la segunda mitad del decenio de los ochenta, acelera la disociación entre la cabecera municipal y las nuevas comunidades emergentes, cuya articulación es casi nula. Hasta tal punto es así que se configuran procesos de suburbanización, en respuesta exclusivamente a lógicas de beneficio inmediato, por parte de agentes externos, que resultan hoy difíciles de gestionar desde los ayuntamientos. 
Por lo demás, la caracterización de las deficiencias y los problemas observados en la configuración del producto turístico residencial, remiten a diferencias en cuanto a estructuras preturísticas, mecanismos de producción y papel de los agentes sociales actuantes.

\section{Incidencia de la política turística}

El turismo residencial no está afectado por una política específica sino que depende de la política turística general y de otras sectoriales (urbanismo, infraestructuras, medio ambiente, etc.). Por tanto, el turismo residencial constituye un «producto-mercado» específico que participa del «producto turístico global» y de los servicios requeridos por un residente habitual del cual se diferencia sociológica, cultural y económicamente.

La gestión de aquellos elementos que inciden en mayor medida en el turismo residencial dependen de la Administración Local, la cual cuenta con una política turística, generalmente menos elaborada que en el resto de administraciones, además de dificultades técnicas y económicas para gestionar la especificidad derivada del turismo residencial.

Es cierto que los presupuestos de turismo representan un montante económico total nada desdeñable, si se atiende a las cantidades absolutas destinadas a este fin. Sin embargo, la importancia del turismo en algunos de los municipios considerados no guarda proporcionalidad con el reducido porcentaje que alcanza la partida de turismo sobre el presupuesto total.

El índice de variación presupuestaria 90-93 pone de manifiesto la variabilidad de los criterios de la política turística municipal. La tendencia general es de crecimiento, aunque no muy acusado; con la excepción de Elche y Villajoyosa que presentan unos índices de variación considerables. Resulta ilustrativo asociar estas tasas de variación con la tendencia de fuerte crecimiento del turismo en sendos municipios. En el otro extremo, los municipios que presentan una índice de variación decreciente (Guardamar, Santa Pola y Benissa) observan un medio (Guardamar) o débil (Santa Pola y Benissa) crecimiento del turismo en su localidad.

La asignación presupuestaria destinada al turismo se circunscribe prácticamente al fomento de la actividad (comunicación en sus diferentes vertientes) ya que los gastos realizados directamente en el producto turístico (globlemente entendido) son casi inexistentes en la partida de turismo (hay excepciones como el apartado de playas en Alicante, en parte porque pertenecen a una misma concejalía) y, dependen, por tanto, de otras partidas presupuestarias diferentes de quien formula o debe formular la política turística.

La mayoría de los municipios cuentan con órganos colaboradores de características similares (Centros de Iniciativas Turísticas, Consejos de Turismo, Patronato Municipal de Turismo, etc.), integrados por representantes del sector y represen- 
tantes políticos de grupos de gobierno y de la oposición. Independientemente de su carácter consultivo, constituyen una necesidad ineludible para la necesaria participación y consenso entre todos los agentes implicados que exige la formulación de la política turística.

Pero, a pesar del interés de estas entidades, no basta su mera existencia y todo parece indicar que la función que actualmente cumplen estos órganos no pasa de ser meramente simbólica.

Todos aquellos municipios que disponen de una Oficina de Información Turística elaboran estadísticas de las visitas a la misma (lo cual no deja de constituir un indicador interesante); sin embargo, salvo casos puntuales, no se obtienen datos sobre el movimiento turístico municipal, información que puede revelar tendencias diversas de la demanda (en cuanto a estacionalidad, recurrencia, fidelidad, previsión, etc.) y de aceptación de la oferta (tendencias de ocupación por tipos de alojamiento,...). Registros estadísticos inherentes a la formulación de una política turística bien estructurada y constantemente actualizada.

Por otro lado, la coordinación entre concejalías suele producirse en la ejecución de las respectivas políticas y no en la fase de formulación o planificación de éstas. Sorprende observar que es el área de cultura la más estrechamente coordinada con turismo, cuando es conocida la escasa relevancia de las actividades culturales en el producto específico de «sol y playa» (en este sentido, es bastante lógica la situación que ocupa el apartado de playas). Por contra, urbanismo, servicios y medio ambiente presentan unos niveles de coordinación con turismo inferiores a los deseables.

En definitiva, las dificultades de desarrollo de la política turística se deben a dos factores principales:

1.- La necesidad de consenso y mutua receptividad entre todos los agentes que intervienen en el turismo.

2.- La escasez de las dotaciones económicas para el turismo.

La relevancia de los dos factores citados no puede ocultar la tendencia a minimizar la trascendencia de la coordinación con otros servicios municipales que afecta directamente a la «política de producto global» $\mathrm{y}$, especialmente, al producto-mercado de turismo residencial.

Por otra parte la colaboración financiera de otras administraciones puede representar un impulso significativo a la política turística municipal

El origen de las subvenciones es, como la tipología de las mismas, diverso. Destacan, cuantitativamente, las ayudas concedidas por el Plan Futures (Secretaría General de Turismo) a los municipios de Alicante y Denia; el ITVA presenta líneas de ayudas diversas ya mencionadas al referirnos a su «Plan de Actuaciones», de las cuales se benefician varios municipios de muestra; mientras que la Diputación Provincial subvenciona a un mayor número de municipios pero con cantidades económicas menores. 
Merece consideración el hecho de que cuatro municipios (Benissa, Jávea, El Pilar de la Horadada y Villajoyosa) no hayan recibido subvención alguna en los dos últimos años, circunstancia que puede aconsejar replantearse las relaciones de la política municipal con las numerosas convocatorias públicas existentes.

En otro sentido, vincular la política turística a la recepción de subvenciones puede generar una relación de dependencia no deseable, síntoma de cierta indefinición e inseguridad en la formulación de esta política, que no surge de las necesidades propias sino que se adapta a las pautas que marcan las convocatorias oficiales de subvenciones.

Es notable el reconocimiento de que, en el contexto actual, el turismo se ha convertido en la base económica de la mayoría de los municipios litorales alicantinos, si bien éstos ofertan un producto en fase de madurez cuya viabilidad futura, independientemente de coyunturas favorables como la de 1994, está pendiente de acciones de reactivación que superen el desequilibrio entre las tendencias actuales de la demanda y la oferta turística existente en el litoral alicantino. El volumen de la oferta residencial en este ámbito y todas las implicaciones que conlleva (económicas, sociales, medioambientales, infraestructurales, etc.) obligan a concentrar en el turismo residencial una dosis importante de los esfuerzos de reactivación turística.

La síntesis de necesidades y definiciones espaciales inherentes al espacio turístico-residencial se plasma a través de estrategias de cualificación de la oferta, cuyos ámbitos de acción son:

— El rediseño territorial de las áreas consolidadas, mediante nuevos elementos y procesos dinamizadores.

- Las orientaciones sobre calidad para las áreas emergentes o en fase de transformación.

- La inserción de nuevos conceptos e ideas, en atención al diagnóstico estratégico bajo enfoque de mercado.

- La especificidad del suelo en áreas turísticas y de sus mecanismos de transformación, explotación y gestión.

- La mejora de los servicios públicos, infraestructuras y entornos turísticos.

- Fomento de la cooperación empresarial y coordinación administrativa.

\section{Estrategias que se proponen}

El Programa de Actuación del Plan MUNRES se concreta mediante tres estrategias, que tienen como eje vertebrador las actuaciones sobre calidad de la oferta.

- Estrategia A: cualificar el producto turístico-residencial y afianzar su competitividad, mediante la construcción de infraestructuras y equipamientos, 
mejora de las dotaciones y servicios y gestión racional del territorio y los recursos naturales y culturales. Esta mejora de la calidad del producto significa obtener una posición de eficiencia, desde la coordinación público-privada, que, en el caso que nos ocupa, atañe a políticas de mejora de las infraestructuras y servicios públicos, sin olvidar que las actuaciones sobre calidad de la oferta exigen, paralelamente a las inversiones públicas, un esfuerzo de los empresarios.

Las demandas de servicios públicos y de infraestructuras configuran la parte del producto turístico que es responsabilidad de las administraciones, especialmente la municipal, y a la que se hace continua referencia entre los requerimientos de los encuestados en áreas turísticas (no olvidar lo que influyen estos aspectos en el grado de satisfacción de la demanda), por lo que será preciso encontrar fórmulas viables de financiación (o cofinanciación en bastantes casos) y de gestión que comporten acciones integradas y coordinadas de distintas administraciones y del mismo sector privado, ya que el papel de los Ayuntamientos no es el de proveedores exclusivos de bienes y servicios para las actividades económicas que se desarrollan en el municipio. Es más, los Ayuntamientos pueden y deben orientar a través de sus inversiones el modelo turístico deseable. Esta es, en resumidas cuentas, una estrategia de Excelencia turística, como la define FUTURES, que, además, integra programas de conservación y mejora del medio ambiente y de gestión racional de los recursos, tema central en el futuro de los espacios turísti$\cos$.

- Estrategia B: establecer nuevas pautas y criterios para el crecimiento de la oferta, desde la idea de un modelo de desarrollo sostenible, lo que supone romper con los mecanismos de consolidación de los espacios urbano-turísticos empleados hasta ahora, ya que no han permitido resolver los problemas existentes e incluso, en no pocos casos, han creado una mala imagen externa. Las acciones encaminadas a la modernización y diversificación de la oferta deben acompañarse de nuevas formas para crear la oferta futura, al tiempo que es preciso elaborar un modelo de regulación de la oferta comercial no reglada y apoyar las iniciativas de mejora - en los asentamientos consolidados - que se llevan a cabo desde las Entidades Urbanísticas de Conservación.

Cuando no ha existido control por los ayuntamientos sobre las obras de urbanización y creación de infraestructura, no es lógico que ahora se pretenda cargar estas deficiencias o falta de terminación de las obras de urbanización sobre los que ya han comprado una vivienda. En todo caso, no es bueno para el prestigio de esta zona como destino del turismo residencial. Una vez deslindadas las áreas que ya se consideren razonablemente consolidadas y apurados los mecanismos para exigir a sus promotores el cumplimiento de las obligaciones contraídas, se trataría de asumir la realidad existente y abrir mecanismos de mejora, cuando así lo acordasen los residentes, mediante contribuciones especiales, que deberían soportar en colaboración con las administraciones. 
El necesario cambio de imagen que se precisa para conseguir el desarrollo sostenible y los cada vez más sofisticados métodos de gestión empresarial, requieren un relevo generacional que ha de nutrirse - $\mathrm{y}$ a su vez obtener trabajo- de las promociones de universitarios y técnicos que han de encontrar empleo en este sector hegemónico de las economías locales. Hecho que apunta a otro tema esencial, que no ha sido tratado en este trabajo, pero que exige esfuerzos considerables: la formación profesional del sector, modelo de calidad de los recursos humanos, profesionalización continuada, oficinas de información, centros educativos, formación especializada para los post-graduados, entre otros aspectos.

El planteamiento y puesta en marcha del Plan MUNRES es, en sí mismo, una medida de promoción y recuperación de estos municipios como destino turístico, cuya imagen se ha deteriorado en los últimos años por el agotamiento del modelo anterior y la competitividad en el escenario internacional. Mejorar el grado de aceptación de los actuales usuarios, requiere resolver los problemas que desprestigian la zona y lanzar una idea inequívoca de que se quiere acoger con agrado a los que han elegido esta zona como destino de su segunda residencia.

- Estrategia C: potenciar la Costa Blanca y su área inmediata como destino residencial supone una clara opción de futuro, avalada por treinta años ininterrumpidos de crecimiento y por las previsiones de la Comunidad Económica Europea. Se trata de hacer de este espacio un destino residencial, notable por su calidad de vida, con la presencia de otras modalidades turísticas y de ocio, junto con la posibilidad de asentamiento de empresas de servicios y tecnología avanzada, que requieran una mano de obra que valore la residencia en unas zonas suficientemente atractivas, con alicientes recreacionales. Un horizonte de mercado con puntos fuertes merced a los niveles de desarrollo alcanzados, pero su consolidación requiere superar los puntos débiles — bastantes también- con un esfuerzo prolongado.

Sentar las bases y marcar la dirección de este esfuerzo pasa por una nueva mentalización de los agentes sociales y la coordinación de las acciones públicas e institucionales que, en cierto modo, ya ha sido iniciado. Por tanto, y en línea con el Plan Estratégico Provincial, se pretende la divulgación de este Plan y el inicio de una serie de grupos de trabajo, confección de Planes Municipales y Comarcales de Ordenación Turística, desarrollo sectorial del citado Plan, completando y coordinando técnicamente los ya existentes.

Ocioso es destacar, como colofón de este documento de síntesis, la necesidad de impulsar, desde el área de Fomento y Turismo de la Diputación Provincial, la aceptación y compromiso por parte de los agentes sociales implicados en la actividad turístico-residencial. Se trata de un esfuerzo de viabilidad para el que resulta imprescindible crear una comisión de seguimiento y participación, con 
representación de empresarios y sindicatos. Pero, sobre todo, es imprescindible trasladar las recomendaciones y propuestas a los Ayuntamientos, a través de jornadas informativas y mesas de trabajo, donde se sustentaría la necesaria concienciación social y necesidad de implantación del nuevo modelo que se propone. 